\title{
Vertebral Bone Drilling (Puncture) Attenuates the Intractable Pain Due to Vertebral Fractures without Collapse
}

\author{
Koichi Ota, Hirosi Nagai \\ Department of Anesthesia, Ebetsu City Hospital, Ebetsu, Japan \\ Email: kota1281@gmail.com
}

Received 10 January 2016; accepted 24 April 2016; published 27 April 2016

Copyright (C) 2016 by authors and Scientific Research Publishing Inc.

This work is licensed under the Creative Commons Attribution International License (CC BY). http://creativecommons.org/licenses/by/4.0/

(c) (i) Open Access

\begin{abstract}
Purpose: Osteoporotic vertebral fractures with no sign of vertebral collapse on initial radiographs, which is so-called occult vertebral fractures (VFs), exist. Occult VFs have a high rate of missed diagnosis, and the treatment of these fractures has rarely been discussed in the literature. We evaluated the effects of vertebral bone drilling for the pain due to occults VFs. Materials and Methods: Eighteen patients with painful osteoporotic occult VFs underwent the vertebral bone drilling. We evaluated the clinical outcome by comparing numerical rating scale (NRS) and activity of daily life (ADL) values between before and after the vertebral bone drilling. Comparisons were made by using Wilcoxon signed rank test. Results: The mean baseline NRS and ADL score, and the mean NRS and ALD score after the bone drilling were $8.4 \pm 0.8,2.2 \pm 0.6,2.4 \pm 1.0,4.6 \pm 0.5$, respectively. Among the patients, we detected significant improvements in NRS pain score and ADL score after the drilling compared with baseline score $(p<0.0002)$. Conclusion: Vertebral bone drilling at the site of painful vertebral compression fractures alleviated the intractable pain due to osteoporotic occult VFs.
\end{abstract}

\section{Keywords}

Vertebral Bone Drilling, Osteoporosis, Occult Vertebral Fractures, Vertebroplasty, Balloon Kyphoplasty, Bone Marrow Edema

\section{Introduction}

Osteoporotic vertebral fractures (VFs) with no sign of vertebral collapse do exist about 20\% [1]. The evaluation of the osteoporotic occult VFs is difficult due to the unapparent radiographic findings [2]. Magnetic resonance 
imaging (MRI) is an important diagnosis tool for the osteoporotic VFs without collapse. The typical MRI findings in acute compression fracture are hypointensity T1-weighted images, hyperintensity or heterogeneous intensity on T2-weighted images, and hyperintensity on fat-suppressed T2-weighted images [3].

Most of the osteoporotic VFs are asymptomatic or minimally symptomatic [4]. The standard treatment for painful VFs consists of conservative medical therapy utilizing analgesics, bed rest, and external bracing. Symptoms typically improve within 4 to 6 weeks [5]. While approximately two-thirds of patients with osteoporotic VFs will respond to conservative therapy alone, a third of the patients managed with conservative medical therapy may not improve and will require alternative treatment [6]. 10\% of the patients will require hospitalization for intractable pain due to VFs [7]. If substantial pain persists after 4 to 8 weeks of nonoperative therapy, interventional therapy like percutaneous vertebroplasty (PVP) and balloon kyphoplasty (BKP) can be considered.

Both PVP and BKP had significant improvement in pain and functional activity after the interventional therapy for painful osteoporotic occult VFs similar to painful osteoporotic VFs with collapse [8].

Yamamoto et al. reported that vertebral bone drilling (BD), which means the PVP without bone cement, attenuated the pain and the back pain related disability like the PVP [9]. We design this study for the assessment of vertebral BD for the pain induced by osteoporotic occult VFs.

\section{Materials and Methods}

\subsection{Study Participants}

Consecutive patients presenting to the pain clinic for painful vertebral compression fractures were screened for enrollment between January 2014 and December 2015. We obtained institutional review board approval and informed consent for all patients. Inclusion criteria were the following: 1) age > 65 years, 2) 1 osteoporotic fracture or more, 3) pain score of at least 5 of 10,4 ) ability to give informed consent. We excluded the patients if they had an infectious disease, tumor involvement of the vertebral bone, diagnosis of multiple myelomas.

53 patients with VFs treated with vertebral BD were retrospectively analyzed. All patients have taken MRI including T1/T2-weighted images and short tau inversion recovery (STIR) sequences. MRI (T1 and STIR sequences) showed bone marrow edema (BME) in all fresh fracture. We evaluated the acute VFs by semiquantitative (SQ) method [10]. Grade 1 in SQ method was defined as $20 \%$ - 25\% decrease in the height of the vertebral body and $10 \%-20 \%$ reduction in the area of the vertebral body. We measured the vertebral height at the anterior wall (A), central position (C), and posterior wall (P). If $A / P \geq 0.9, C / A \geq 0.9$, and $C / P \geq 0.9$, the change area of the vertebral body is within $10 \%$. We classified the VFs as grade 0 which mean the occult VFs.

We enrolled 18 of 53 patients, whose VFs were all grade0 in SQ method, treated vertebral BD in this study.

\subsection{Collection of Baseline Variables}

Baseline data collection included age, gender, weight, height and the duration in the hospital. Outcome measures collected at baseline included a 0 - 10 rating of average pain (NRS) during 24 hours, and ADL was evaluated using the following 5-point scale: 1 ) bedridden and total assistance; 2) mostly bedridden and able to sit on the bed; 3) needing a wheelchair for movement; 4) able to walk with a stick; 5) complete independence.

\subsection{Procedural Characteristics}

We escorted the patients to a fluoroscopy room after screening and written informed consent. All procedures were performed under strict aseptic conditions. Patients placed decubitus posture on the fluoroscopy table. We used fluoroscopy for localization of the vertebral bodies. A 1-inch 25-gauge needle used to raise a wheel of $1 \%$ lidocaine subcutaneously. A 12-cm 22-gauge block needle placed into the skin at the site of the wheel and advanced under fluoroscopic guidance to the periosteum over the pedicle (Figure 1). After infiltration with $1 \mathrm{ml}$ of $1 \%$ lidocaine at the spots, we drilled vertebral bones until the bone marrow. When the cortex was penetrated, the marrow was aspirated from an attached syringe. A small account of contrast medium injected to verify that the needle tip was within the marrow. After stopping backflow from the needle, we removed the needle. We compressed the wound for several minutes.

\subsection{Outcome Measures and Analysis}

We assessed primary outcome measures in the NRS scores (average during the past 24-hours) and ADL scores 


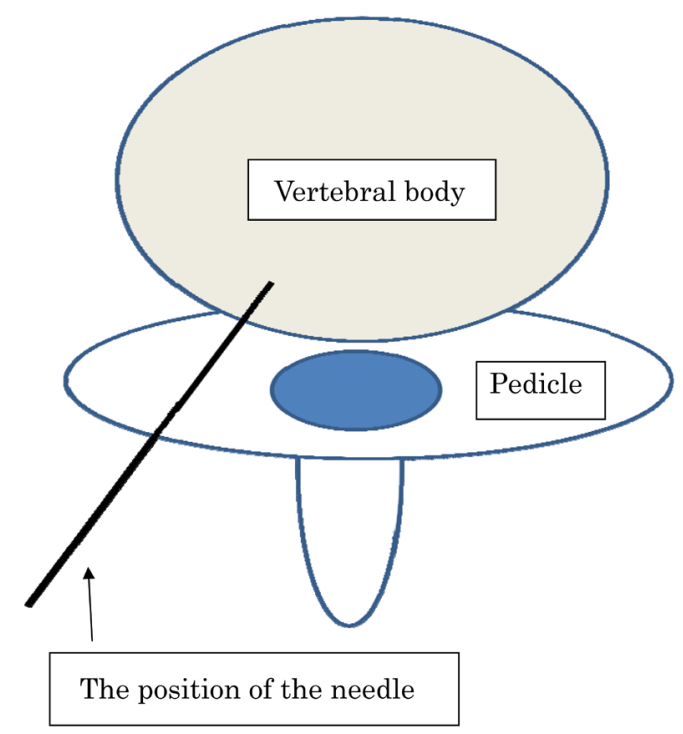

Figure 1. Pedicle approach and the position of the needle tip.

at the discharge day from the hospital. Comparisons were made by using Wilcoxon rank sum test. Descriptive statistics determined by calculation of the mean and standard deviation (SD). Results presented as mean \pm SD, and statistical significance defined as $\mathrm{p}<0.05$.

\section{Results}

\subsection{Patient Factors}

A total of 18 patients with 28 osteoporotic occult VFs were enrolled in this study. The patient's characteristics are shown in Table 1. Eight patients had one osteoporotic VF. 10 patients had two osteoporotic VFs, the levels treated were two L1, one L2, seven L3, eight L4, ten L5.

\subsection{Improvement in Function and Pain after Vertebral BD}

Among the 18 patients enrolled in this study, NSR and ADL scores at the baseline data and the discharge day from the hospital are presented in Table 2. There were significant improvements in average NRS score during 24 hours compared with baseline $(\mathrm{p}<0.0002)$. A significant improvement was noted in the ADL scores at the discharge day compared with baseline $(\mathrm{p}<0.0001)$.

\section{Discussion}

Intervention therapy like PVP and BKP became a popular treatment for symptomatic VFs [5]. Vertos II [11] and FREE trial [12], which compared PVP or BKP to traditional conventional management, show the efficacy of PVP and BKP for painful VFs. On the contrary, Two independent placebo-controlled RCT studies [13] [14] found PVP to be equivalent to a sham intervention. The sham procedure was simulated the PVP without injection of cement. The two groups were a similar reduction in pain and improvements in back pain-related disability in acute and chronic phase. Buchbinder R. et al. [15] found no demonstrable clinically useful benefits compare with a sham procedure and open trials comparing PVP and BKP with usual conservative care are likely to have overestimated any benefit of PVP and BKP. They recommend that patients should be informed about both the lack of high-quality evidence supporting the merit of PVP and BKP and its potential for harm.

Kohashi et al. [16] reported that vertebral body decompression (puncture) which means the PVP without cement decreased the pain and improved the back pain-related disability. On the contrary, periosteum vertebral infiltration of local anesthetics did not reduce the intractable pain due to vertebral compression fracture [17]. These reports show us vertebral BD is essential for attenuation of the pain due to vertebral compression fractures. 
Table 1. Patient's characteristics.

\begin{tabular}{cc}
\hline Male:Female & $3: 15$ \\
Age (years) & $78.4 \pm 9.1$ \\
Height (cm) & $151.0 \pm 8.0$ \\
Body weight (kg) & $50.8 \pm 11.2$ \\
Duration in the hospital (days) & $28.8 \pm 14.1$ \\
\hline
\end{tabular}

Table 2. Improvement in Function and pain after vertebral BD.

\begin{tabular}{cccc}
\hline & Baseline & The discharge day & p-value \\
\hline NRS during the past 24 hours & $8.4 \pm 0.7$ & $2.4 \pm 1.0$ & $<0.0002$ \\
ADL & $2.2 \pm 0.6$ & $4.6 \pm 0.5$ & $<0.0001$ \\
\hline
\end{tabular}

BD, Bone Drilling; NRS, Numerous Rating Scale; ADL, Activity of Daily Life.

Vertebral body puncture, which is similar to BD, is a minimally invasive therapy compared with PVP and BKP [18]. While it is important the position of the needle placement and viscosity of the cement to reduce the risk of cement leakage in PVP and BKP, the position of the needle tip for BD is enough in the margin of the vertebral body because of no need to cement injection. In our experience [19], we performed the unilateral technique using a transpedicular approach and used a 22-gauge needle in BD. Bilateral technique and thick needles (8 - 13gauge) are often used in PVP and BKP. Hence, BP is a minimally invasive therapy to treat painful osteoporotic VFs compared with PVP and BKP. Probable complications of BD are hemorrhage, infection, dural puncture, nerve damage, ectopic tissue injury, and fracture. We did not experience any adverse effect in our study.

Vertebral bone bruise (VBB), also known as trabecular microfractures, is defined on MRI as BME without the associated fracture of the cortex [20]. At a follow-up of 19 months study, VBB with vertebral fracture does not appear to cause significant progressive vertebral deformity, and 3 of 30 VFs in 18 patients remained no collapse [21]. A follow-up the study of Pham T et al. (1), 4 of 21 VFs in 16 patients remained normal. Other paper [22] reported 5 of 95 VFs in 34 patients was occult VFs

Intervertebral cement infusion like PVP and BKP exerts analgesic effect and the resolution of vertebral deformities [23]. However, in those without vertebral mobility like occult VFs, the analgesic effects of PVP are the same regardless of bone cement infusion [24]. There are some perioperative and postoperative adverse events associate with both PVP and BKP, such as systemic cement leakage, cement embolism, pulmonary embolism, spinal cord compression [25]. The incident of procedure-related complications of PVP and BKP, such as bone cement leakage, pulmonary embolism, and so on, does not happen in BD because of no injection of bone cement.

Elderly patients suffering from osteoporotic VFs prefer to accept a minimally invasive therapy, because of their frail physical status and morbid medical conditions. Appropriate patient selection, pre-procedural evaluation, and meticulous attention to proper technique are important to achieve good outcomes and minimized complications. The patients suffering from osteoporotic VFs without collapse are preferred to BD, which is a minimally invasive therapy compare with PVP and BKP.

\section{Conclusion}

Vertebral BD at the site of painful vertebral VFs without collapse attenuated the acute intractable pain and improved in the pain-related disability due to osteoporotic VFs.

\section{References}

[1] Pham, T., Azulay-Porrado, J., Chagnaut, C., Legre, V. and Lafforgue, P. (2005) “Occult” Osteoporotic Vertebral Fractures: Vertebral Body Fractures without Radiologic Collapse. Spine, 21, 2430-2435. http://dx.doi.org/10.1097/01.brs.0000184303.86932.77

[2] Kim, Y.J., Chae, S.U., Kim, G.D., Park, K.H., Lee, Y.S. and Lee, H.Y. (2013) Radiographic Detection of Osteoporotic Vertebral Fracture without Collapse. Journal of Bone Metabolism, 20, 89-94. 
http://dx.doi.org/10.11005/jbm.2013.20.2.89

[3] Tanigawa, N., Komemushi, A., Kariya, S., Kojima, H., Shomura, Y., Ikeda, K., Omura, N., Murakami, T. and Sawada, S. (2006) Percutaneous Vertebroplasty: Relationship between Vertebral Body Bone Marrow Edema Pattern on MR Images and Initial Clinical Response. Radiology, 239, 195-200. http://dx.doi.org/10.1148/radiol.2391050073

[4] Ross, P.D. (1997) Clinical Consequences of Vertebral Fractures. The American Journal of Medicine, 103, 30S-42S, Discussion 42S-43S.

[5] Jay, B. and Ahn, S.H. (2013) Vertebroplasty. Seminars in Interventional Radiology, 30, 297-306. http://dx.doi.org/10.1055/s-0033-1353483

[6] Klazen, C.A., Verhaar, H.J., Lohle, P.N., Lampmann, L.E., Juttmann, J.R., Schoemaker, M.C., van Everdingen, K.J., Muller, A.F., Mail, W.P. and de Vries, J. (2010) Clinical Course of Pain in Acute Osteoporotic Vertebral Compression Fractures. Journal of Vascular and Interventional Radiology, 21, 1405-1409. http://dx.doi.org/10.1016/j.jvir.2010.05.018

[7] Kim, D.H. and Vaccaro, A.R. (2006) Osteoporotic Compression Fractures of the Spine; Current Option and Considerations for Treatment. The Spine Journal, 6, 479-487. http://dx.doi.org/10.1016/j.spinee.2006.04.013

[8] Mao, H., Zou, J., Geng, D., Zhu, X., Zhu, M., Jiang, W. and Yang, H. (2012) Osteoporotic Vertebral Fractures without Compression: Key Factors of Diagnosis and Initial Outcome of Treatment with Cement Augmentation. Neuroradiology, 54, 1137-1143. http://dx.doi.org/10.1007/s00234-012-1018-8

[9] Yokoyama, K., Kawanishi, M., Yamada, M., Tanaka, H., Ito, Y., Hirano, M. and Kuroiwa, T. (2012) Comparative Study of Percutaneous Vertebral Body Perforation and Vertebroplasty for the Treatment of Painful Vertebral Compression Fractures. American Journal of Neuroradiology, 33, 685-689. http://dx.doi.org/10.3174/ajnr.A2847

[10] Genant, H.K., Wu, C.Y., van Kuijk, C. and Nevitt, M.C. (1993) Vertebral Fracture Assessment Using a Semiquantitative Technique. Journal of Bone and Mineral Research, 8, 1137-1148. http://dx.doi.org/10.1002/jbmr.5650080915

[11] Klazen, C.A., Lohie, P.N., de Vries, J., Jansen, F.H., Tiebeek, A.V., Blonk, M.C., Vermans, A., van Rooij, W.J., Schoemaker, M.C., Juttmann, J.R., Lo, T.H., Verhaar, H.J., van der Graaf, Y., Muller, A.F., Elgersma, O.E., Halkema, D.R., Fransen, H., Janssen, X., Buskens, E. and Mali, W.P. (2010) Vertebroplasty versus Conservative Treatment in Acute Osteoporotic Vertebral Compression Fractures (Vertos II): An Open-Label Randomized Trial. The Lancet, 376, 1085-1092. http://dx.doi.org/10.1016/S0140-6736(10)60954-3

[12] Wardlaw, D., Cummings, S.R., Van Meirhaeghe, J., Bastian, L., Tillman, J.B., Ranstam, J., Eastell, R., Dhabi, P., Talmadge, K. and Boonen, S. (2009) Efficacy and Safety of Balloon Kyphoplasty Compared with Non-Surgical Care for Vertebral Compression Fracture (FREE): A Randomized Controlled Trial. The Lancet, 373, 1016-1024. http://dx.doi.org/10.1016/S0140-6736(09)60010-6

[13] Buchbinder, R., Osborne, R.H., Ebeling, P.H., Ebeling, P.R., Wark, J.D., Mitchell, P., Wriedt, C., Graves, S. and Staple, M.P. (2009) A Randomized Trial of Vertebroplasty for Painful Osteoporotic Vertebral Fractures. The New England Journal of Medicine, 361, 557-568. http://dx.doi.org/10.1056/NEJMoa0900429

[14] Kallmes, D.F., Comstock, B.A., Heagerty, P.J., Heagerty, P.J., Turner, J.A., Wilson, D.J., Daiamond, T.H., Edwards, R., Gray, L.A., Stout, L., Owen, S., Hollingworth, W., Ghdoke, B., Annesley-Williams, D.J., Ralston, S.H. and Jarvik, J.G. (2009) A Randomized Trial of Vertebroplasty for Osteoporotic Spinal Fractures. The New England Journal of Medicine, 361, 569-579. http://dx.doi.org/10.1056/NEJMoa0900563

[15] Buchbinder, R., Golmohammadi, K., Johnston, R.V., Owen, R.J., Homik, J., Jones, A., Dhillon, S.S., Kallmes, D.F and Lambert, R.G. (2015) Percutaneous Vertebroplasty for Osteoporotic Vertebral Compression Fracture. Cochrane Database of Systematic Reviews, 4, Article ID: CD006349. http://dx.doi.org/10.1002/14651858.CD006349.pub2

[16] Kohashi, Y., Matsuura, T., Ishitani, E., Shin, K. and Sonoda, Y. (2006) The Experience of Decompression of Internal Pressure in Vertebra Body for Painful Osteoporotic Thoracolumbar Compression Fractures. Orthop Surg Traumatol, 49, 833-839.

[17] Brinjikji, W., Comstock, B.A., Gray, L. and Kallmes, D.F. (2010) Local Anesthesia with Bupivacaine and Lidocaine for Vertebral Fracture Trial (LABEL): A Report of Outcomes and Comparison with the Investigational Vertebroplasty Efficacy and Safety Trial (INVEST). AJNR, 31, 1631-1634. http://dx.doi.org/10.3174/ajnr.A2145

[18] Yamada, M., Yokoyama, K., Kawanishi, M., Tanaka, H., Ito, Y., Hirano, M. and Kuroiwa, T. (2013) Prospective Assessment of Pain and Functional Status after Percutaneous Vertebral Body-Perforation Procedure for Treatment of Vertebral Compression Fracture. Neurologia Medico-Chirurgica (Tokyo), 53, 71-76. http://dx.doi.org/10.2176/nmc.53.71

[19] Ota, K. and Iwasaki, S. (2014) Vertebral Bone Drilling (Puncture) Attenuates the Acute Pain Due to Vertebral Compression Fractures. Open Journal of Anesthesiology, 4, 46-49. http://dx.doi.org/10.4236/ojanes.2014.42007

[20] Eustace, S., Keogh, C., Hedlund, R., Blake, M., Ward, R.J., Oder, P.D. and Dimasi, M. (2001) MR Imaging of Bone Oedema: Mechanisms and Interpretation. Clinical Radiology, 56, 4-12. http://dx.doi.org/10.1053/crad.2000.0585

[21] Teli, M., Roeck, N.D., Horowitz, M.D., Saifuddin, A., Green, R. and Noordeen, H. (2005) Radiographic Outcome of 
Vertebral Bone Bruise Associated with Fracture of the Thoracic and Lumbar Spine in Adults. European Spine Journal, 14, 541-545. http://dx.doi.org/10.1007/s00586-004-0786-1

[22] Kanchiku, T., Taguchi, T. and Kawai, S. (2003) Magnetic Resonance Imaging Diagnosis and New Classification of the Osteoporotic Vertebral Fracture. Journal of Orthopaedic Science, 8, 463-466. http://dx.doi.org/10.1007/s00776-003-0665-3

[23] Yokoyama, K., Kawanishi, M., Yamada, M., Tanaka, H., Ito, Y., Hirano, M. and Kuroiwa, T. (2013) In Not Only Vertebroplasty but Also Kyphoplasty, the Resolution of Vertebral Deformities Depends on Vertebral Mobility. AJNR, 34, 1474-1476. http://dx.doi.org/10.3174/ajnr.A3424

[24] Yokoyama, K., Kawanishi, M., Yamada, M., Tanaka, H., Ito, Y., Hirano, M. and Kuroiwa, T. (2013) Validity of Intervertebral Bone Cement Infusion for Painful Vertebral Compression Fractures Based on the Presence of Vertebral Mobility. AJNR, 34, 228-232. http://dx.doi.org/10.3174/ajnr.A3160

[25] Yimin, Y., Zhiwei, R., Wei, M. and Jha, R. (2013) Current Status of Percutaneous Vertebroplasty and Percutaneous Kyphoplasty-A Review. Medical Science Monitor, 19, 826-836. http://dx.doi.org/10.12659/MSM.889479

\section{Abbreviations}

VFs: Vertebral Fractures

NRS: Numerical Rating Scale

ADL: Activity of Daily Life

MRI: Magnetic Resonance Imaging

PVP: Percutaneous Vertebroplasty

BKP: Balloon Kyphoplasty

BD: Bone Drilling

STIR: Short Tau Inversion Recovery

BME: Bone Marrow Edema

SQ: Semiquantitative

SD: Standard Deviation

RCT: Randomized Controlled Trial

VBB: Vertebral Bone Bruise 